\title{
Measles in Children With HIV Infection: Report of Five Cases
}

\author{
Vânia de Carvalho ${ }^{1}$, Leide Parolin Marinoni ${ }^{1}$, \\ Luzilma Flenick Martins ${ }^{2}$, Kerstin Taniguchi ${ }^{1}$, \\ Cristina Rodrigues da $\mathrm{Cruz}^{2}$, Jeanine Bertogna ${ }^{1}$ \\ and José Fillus Neto ${ }^{3}$
}

\author{
Pediatric Dermatology Division ${ }^{1}$, Pediatric Infectology \\ Division $^{2}$, Pathology Department ${ }^{3}$, ClinicalHospital, \\ Federal University of Paraná, Curitiba, PR, Brazil
}

\begin{abstract}
Patients with AIDS have a high incidence of skin problems due to the immunosuppression and malnourishment that are inherent to the progression of this disease. Clinical manifestation of these skin lesions and their severity are different in AIDS patients. We made a prospective study of five cases of measles in children with HIV infection during a community outbreak, and there were typical as well as atypical forms of the disease, including one case with negative serology. There were pulmonary complications, but none of the patients died. The anti-retroviral treatment may have contributed to the decrease in measles morbidity in these pediatric AIDS patients. Key Words: AIDS, measles, children.
\end{abstract}

Exanthemas are very frequent in pediatric practice, and a detailed clinical history is very important to establish etiological diagnosis [1]. Some of the exanthemas show systemic manifestations and skin lesions that are common in many other diseases, like those caused by echovirus and adenovirus. Others have well-defined clinical characteristics that allow their differentiation, such as rubella and measles [2].

Measles is an exanthematic contagious disease caused by a paramyxovirus, with skin and mucosal involvement due to the direct action of the virus [3]. Pulmonary complications can occur and mortality is higher in the malnourished patient [4]. Activeimmunization can protect almost $98 \%$ of affected children [5].

AIDS may cause a loss of anti-measles antibodies (acquired by active natural or artificial means) as the immunodeficiency progresses, reaching non-protective levels [6], increasing the susceptibility to this disease

Received on 15 June 2003; revised 19 September 2003.

Address for correspondence: Dr..Vânia Oliveira de Carvalho. Rua Richard Strauss, 62, Vista Alegre, Curitiba, Paraná, Brazil, Zip code: 80820-110. Phone: (55 41) 338-8318. Fax: (55 41) 3353477.E-mail: rcarvalho50@hotmail.com

The Brazilian Journal of Infectious Diseases 2003;7(5):346-352 (c) 2003 by The Brazilian Journal of Infectious Diseases and Contexto Publishing. All rights reserved.
[7]. The immunosuppression that succeeds measles, associated with AIDS immunosuppression, may increase mortality $[4,8]$, because both viruses infect the $\mathrm{T} \mathrm{CD}_{4}$ lymphocyte [9].

We examined the clinical and laboratory characteristics of measles in five pediatric AIDS patients treated with anti-retroviral drugs. These patients were selected from a prospective study that evaluated 40 children with AIDS, during six months, from March 1997 to February 1998. Their clinical and immunological status were analyzed and they were examined for skin lesions. This study was approved by the UFPR - Clinical Hospital - Ethics and Human Being Research Committee and informed consent was obtained for all patients.

The Center for Diseases Control's criteria were used for AIDS diagnosis [10]. Patients were classified into clinical categories, according to clinical manifestations, as $\mathrm{N}, \mathrm{A}, \mathrm{B}$ and $\mathrm{C}$, and into immunological categories, according to the $\mathrm{T} \mathrm{CD}_{4}$ lymphocyte numbers, as 1,2 and $3[10]$.

The number of HIV RNA viral copies (viral load) was determined by the NASBA technique and $\mathrm{TCD}_{4}$ lymphocyte values by a flow cytometry immunofluorescence study. Measles diagnosis included clinical data and antibody determination of IgM measles antibodies by enzyme immunoassay. 


\section{Case Reports}

Five children with AIDS had clinical and laboratory diagnosis of measles during July - August 1997. Their mean age was 3.5 years ( 2 to 5 years), and only one patient weighed under the 2 nd percentile, following Marques criteria [11]. HIV transmission was perinatal and all patients received antiretroviral treatment (Table 1). It was found that three cases were due to exposure at school, and exposure was nosocomial in two cases (1 and 2). There was evidence of complete vaccination for measles in cases 2 and 3 , given at 9 months and 15 months, respectively.

All patients presented coryza, coughing and fever for four days preceding skin lesions. The exanthema was typical in three patients (cases 1, 3 and 4) with cephalocaudal progression of confluent lesions (Figure 1) and two patients had Koplik's spots on the buccal mucosa. Only bilateral lesions in the malar region, which persisted for 20 days (Figure 2), were observed in case 2. Case 5 presented a generalized erythematous micropapular exanthem during 24 hours (Figure 3 ), followed by erythematous macular lesions on the malar region that lasted for 15 days. Measles serology was negative in case 1 , belonging to the $\mathrm{C} 3$ category, with a viral load above 100,000 copies $/ \mathrm{ml}$, corresponding to severe immunosuppression. Clinical presentation of this case was typical, the contact was nosocomial and he died of wasting syndrome six months after the diagnosis of measles. The clinical-immunological classification, viral load and clinical characteristics of the five cases are shown in Table 2.

A biopsy specimen was taken in case 3 ; the first diagnosis was pharmacodermia, with moderate regular acanthosis of the epidermis, and mild spongiosis and exocytosis of the lymphocytes and polymorphonuclear cells. There were necrotic keratinocytes in the spinal layer and a mild perivascular infiltrate in the upper dermis, composed mainly of inflammatory cells. Red cell extravasation in the deep dermis and hypodermis was also found. A histological diagnosis of spongiotic dermatitis with discrete chronic peri-vascular inflammation, compatible with viral infection, was given (Figure 4).
One patient belonging to category $\mathrm{C} 1$, and two patients in category $\mathrm{C} 3$, had pulmonary complications (bronchopneumonia) and they received antibiotics I.V. (ceftazidime and vancomycin in cases 1 and 2, and ceftriaxone in case 4). Oxygen was not necessary. No children died because of measles or its immediate complications.

\section{Discussion}

Measles prophylaxis by active immunization provides immunity in $98 \%$ of the cases [5]. This disease had been under control in the state of Paraná until 1997 and probably due to the small number of individuals without an immunological response, and the presence of susceptible adults, there was an outbreak in 1997 and 1998 [11].

The five cases of measles in AIDS pediatric patients coincided with an outbreak of measles in the community, which explains its high frequency $(12.5 \%)$ in this study. Other authors studying AIDS in children did not report any cases of measles [12-15].

Nosocomial exposure occurred in two cases: case 1 , who was in a emergency service where a case of measles was registered and case 2, who was hospitalized with patient 1 .

Palumbo also observed nosocomial exposure in four of six cases [6]. Due to the high vulnerability of AIDS patients to other diseases, they should be attended in places where they have no contact with patients suffering from acute diseases.

In case 3 , the initial diagnosis was a drug eruption. A histological study showed necrotic keranocytes in the upper dermis; later the serology indicated a diagnosis of measles. Similar findings in a skin biopsy were described by Mc Nutt et al. [16] in an infant with AIDS who did not develop anti-measles antibodies. In typical cases of this disease, with negative serology, a skin biopsy can indicate a diagnosis as groups of necrotic keranocytes are found in the upper spinal layer and in the granular spinal layer of the epidermis. These histological findings are similar to those found in erythema multiforme, but in the latter the necrotic keranocytes are situated in the basal layer [16]. 
Table 1. Age, weight, and antiretroviral treatment

\begin{tabular}{|c|c|c|c|c|c|}
\hline Patients & Age & Weight & Antiretroviral treatment & $\mathrm{CD}_{4}$ & Viral load \\
\hline Case 1 & $2 \mathrm{y} 5 \mathrm{~m}$ & $\begin{array}{c}8,9 \mathrm{~kg} \\
3 \downarrow 2.5 \mathrm{P}\end{array}$ & AZT, ritonavir, nelfinavir & 15 & $3,200.000$ \\
\hline Case 2 & $4 y 9 m$ & $\begin{array}{c}17 \mathrm{~kg} \\
(75 \mathrm{P})\end{array}$ & AZT, ritonavir, 3TC & 210 & 440,000 \\
\hline Case 3 & $3 y 9 \mathrm{~m}$ & $\begin{array}{l}12.8 \mathrm{~kg} \\
(2.5 \mathrm{P})\end{array}$ & AZT, 3TC & 2830 & 13,000 \\
\hline Case 4 & $5 y$ & $\begin{array}{c}15 \mathrm{~kg} \\
(10 \mathrm{P})\end{array}$ & AZT, D4T & 1360 & 150,000 \\
\hline Case 5 & $3 y 4 m$ & $\begin{array}{c}15.5 \mathrm{~kg} \\
(50 \mathrm{P})\end{array}$ & AZT, 3TC & 535 & 4,800 \\
\hline
\end{tabular}

AZT - zidovudine, 3TC lamivudine, D4T - estavudine.

Table 2. Measles characteristics in children with HIV infection

\begin{tabular}{|c|c|c|c|c|c|c|}
\hline $\begin{array}{l}\text { Patients } \\
\text { Category } \\
\text { Viral load }\end{array}$ & Clinical data ${ }^{2}$ & Exanthema & Koplick's sign & $\begin{array}{c}\text { Exanthema } \\
\text { duration }\end{array}$ & Complication & Sorology \\
\hline $\begin{array}{c}\text { Case } 1 \\
\text { C3 } \\
>100,000\end{array}$ & + & $\begin{array}{l}\text { Maculo } \\
\text { papular } \mathrm{E}^{3} \\
\text { Disseminated }\end{array}$ & + & 15 days & Pneumonia & - \\
\hline $\begin{array}{c}\text { Case } 2 \\
\text { C3 } \\
>100,000\end{array}$ & + & $\begin{array}{l}\text { Maculo } \\
\text { papularE } \\
\text { Malar }\end{array}$ & - & 20 days & Pneumonia & + \\
\hline $\begin{array}{c}\text { Case } 3 \\
\text { B1 } \\
<100,000\end{array}$ & + & $\begin{array}{l}\text { Maculo } \\
\text { papular E } \\
\text { Disseminated }\end{array}$ & - & 08 days & No & + \\
\hline $\begin{array}{c}\text { Case } 4 \\
\text { C2 } \\
>100,000\end{array}$ & + & $\begin{array}{l}\text { Maculo } \\
\text { papular E } \\
\text { Disseminated }\end{array}$ & + & 10 days & Pneumonia & + \\
\hline $\begin{array}{c}\text { Case } 5 \\
\text { B2 } \\
<100,000\end{array}$ & + & $\begin{array}{l}\text { Micro-papular } \\
\text { Skin color } \\
\text { Disseminated } \\
\text { Maculo } \\
\text { papularE } \\
\text { Malar }\end{array}$ & - & 15 days & No & + \\
\hline
\end{tabular}

1.Clinical immunological categories; 2. Cough, coryza and fever; 3. E - Erythematous. 
Figure 1. Typical skin lesions of measles, showing pinhead-sized papules on an erythematous base.

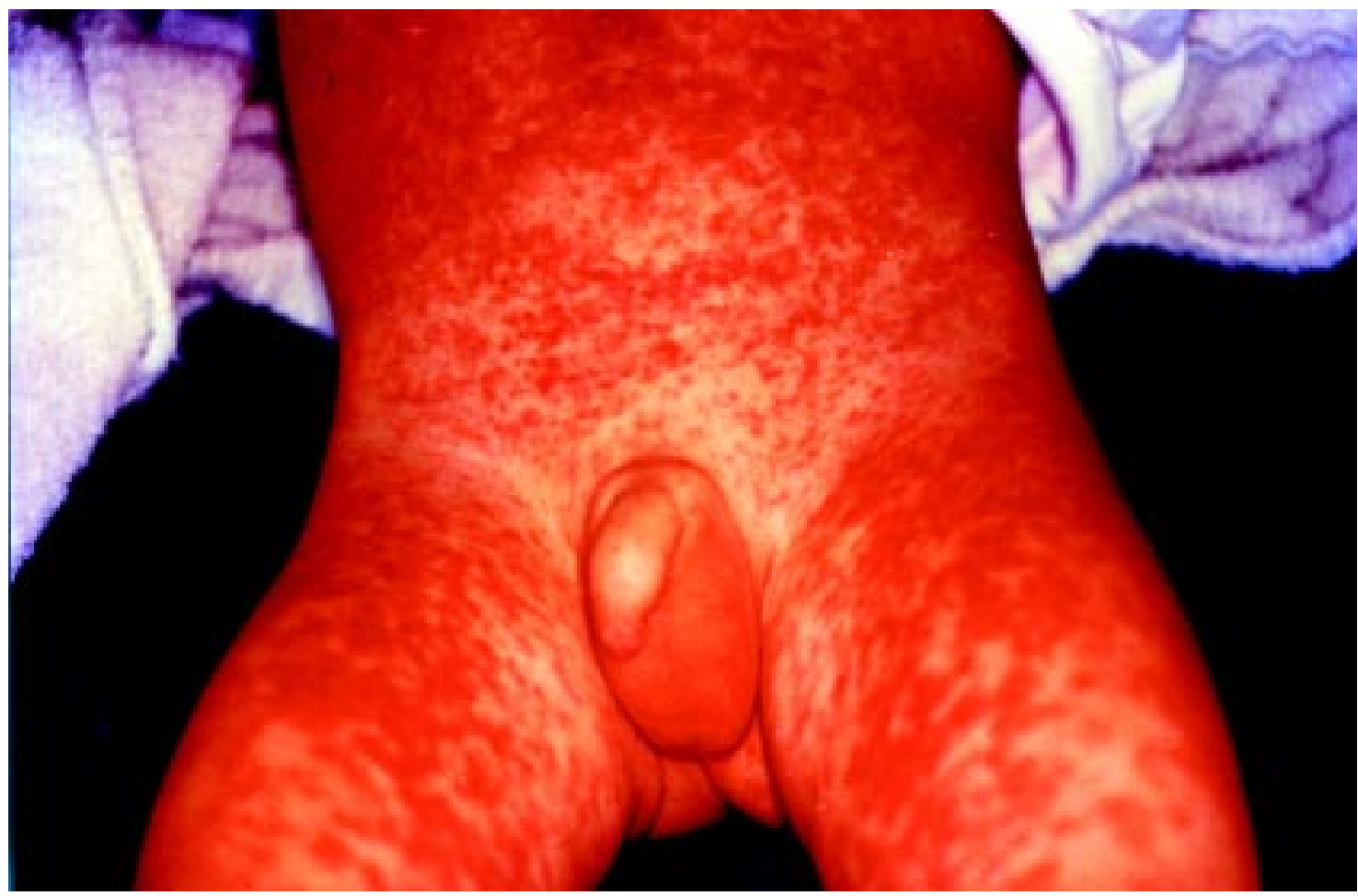

Figure 2. Measles - mild erythematous lesions on the malar region.

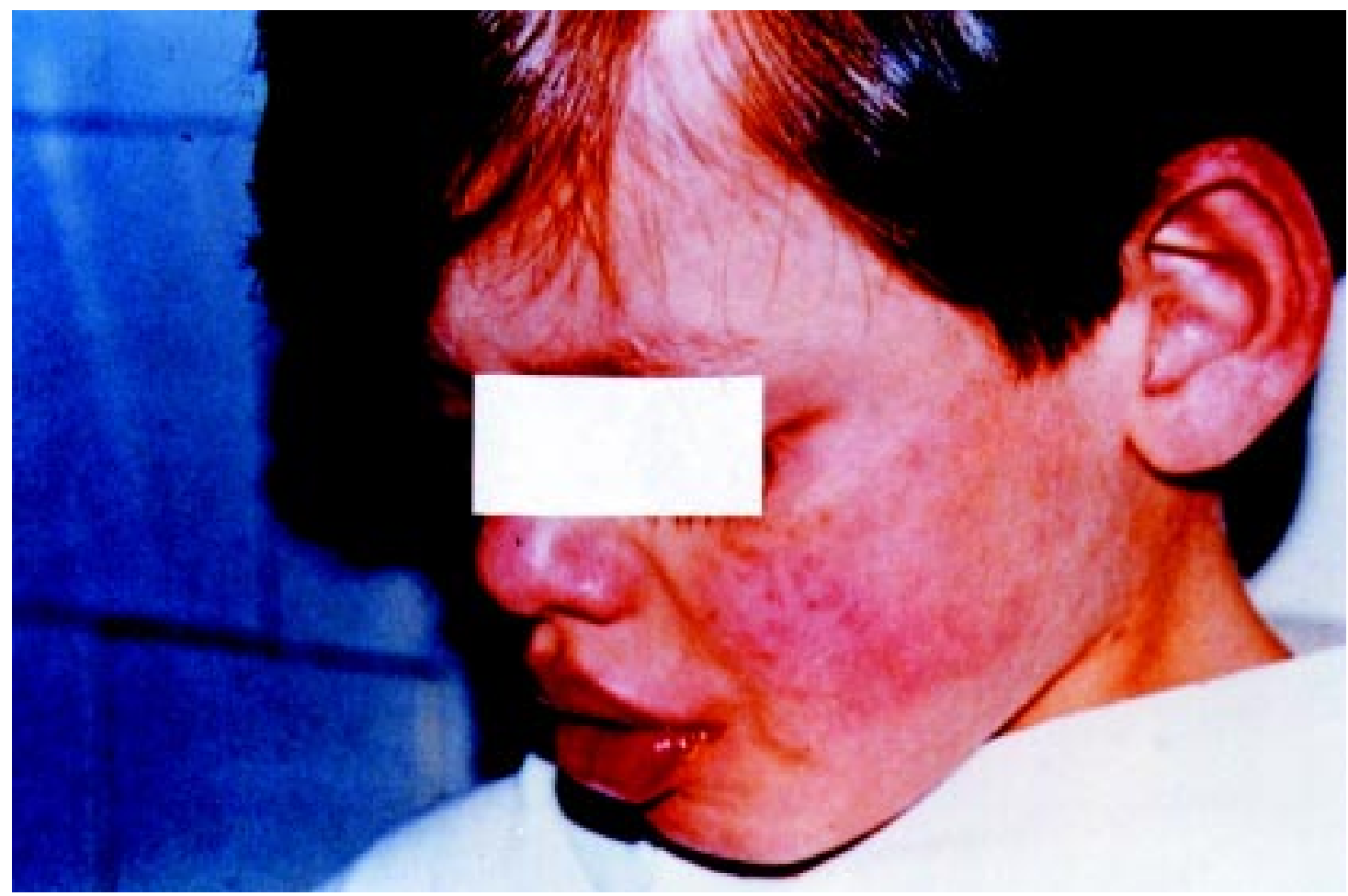


Figure 3. Measles- mild erythematous papules.

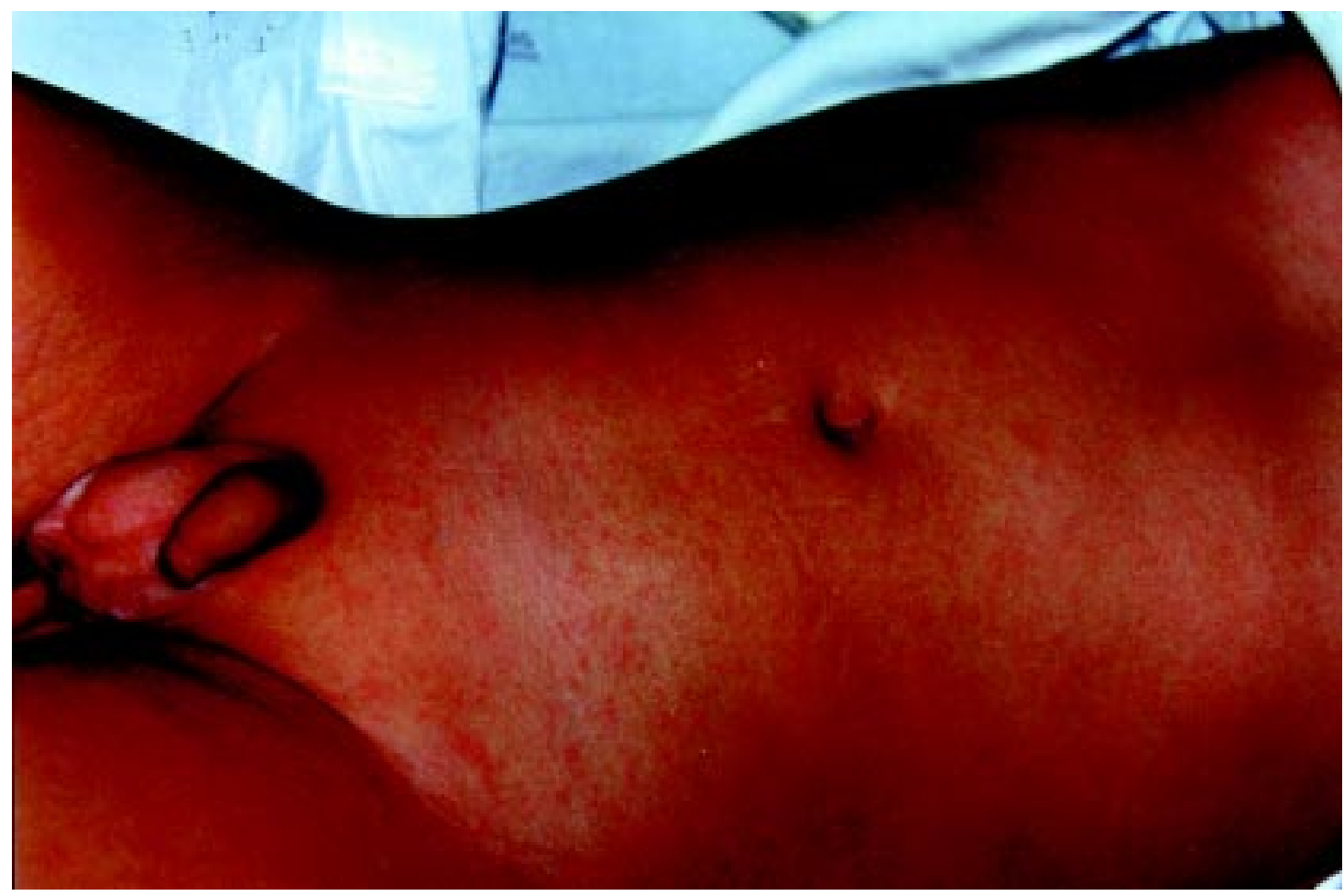

Figure 4. Epidermis presenting necrotic keratinocytes in the spinous layer (hematoxylin eosin 400X).

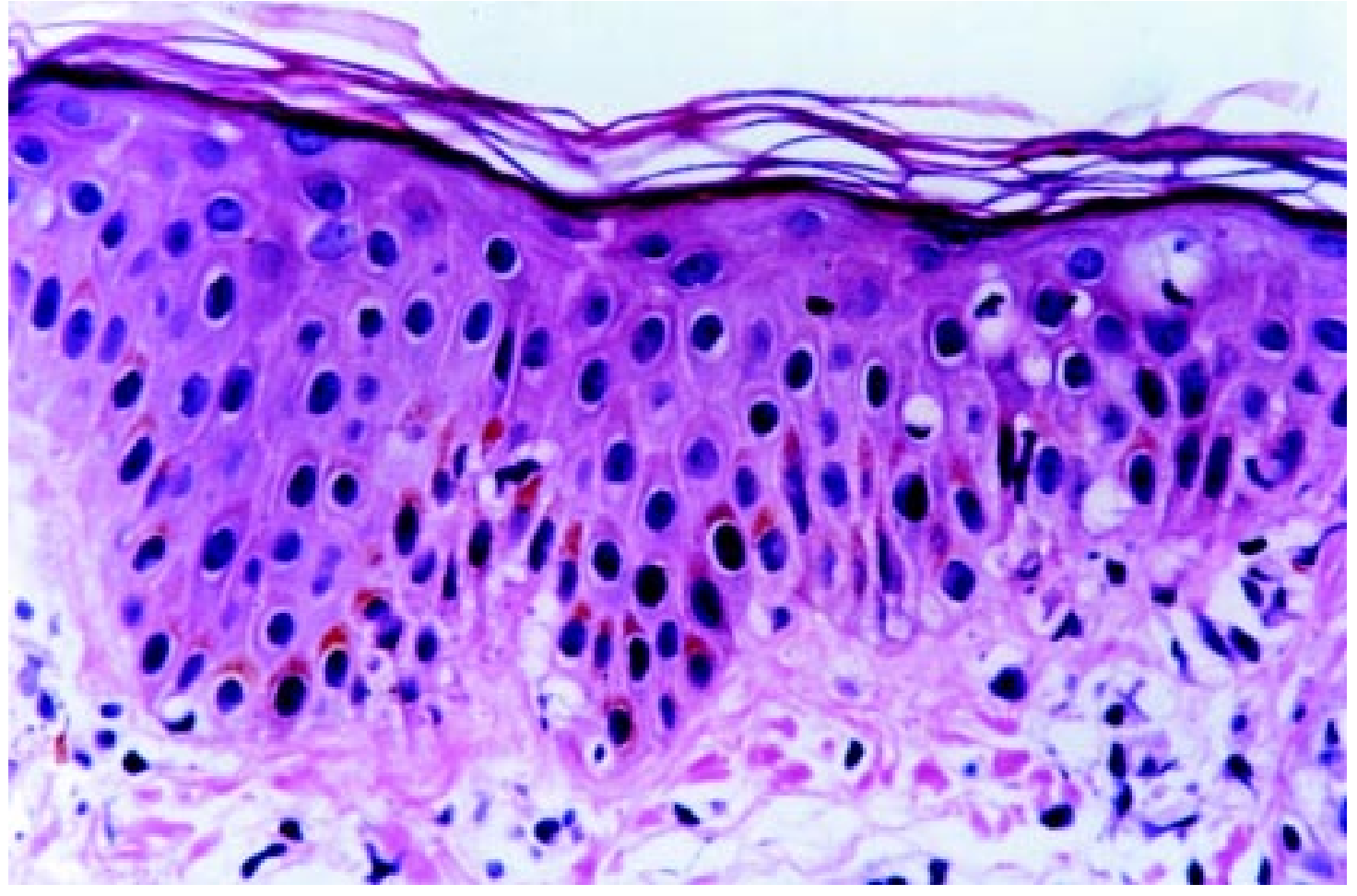


In one of the children in our study no IgM anti-measles antibodies were found. This patient showed severe immunosuppression and the diagnosis was based on epidemiology (nosocomial contact) and the presence of the typical exanthema and "Koplick's" spot. The severity of immunosuppression found in this patient may explain the absence of antibodies and the negative serology. All the other cases were confirmed by serology.

Two patients had received complete immunization vaccinations. The effectiveness of immunization against measles in children with AIDS has not yet been determined [17]. Palumbo et al. [6] found that in a group of 80 children with AIDS immunized against measles, 36\% did not develop antibodies. Also a loss of antibodies acquired by active or passive pathways may occur in pediatric population with AIDS. In adult patients with AIDS the loss of antibodies is rare because most of these patients acquired measles during childhood, when the immune system was intact [18].

Complete vaccination and a previous diagnosis of measles in patients with AIDS do not exclude the possibility of a new episode of this disease. This possibility should be remembered, especially when there is a positive epidemiological history.

Patients with AIDS, even those already vaccinated against measles, must receive active immunization during outbreaks of this disease, and those who are exposed to measles must receive passive immunization with gama globulin, due to the possibility of a loss of antibodies [4].

Children with AIDS who present measles even after being immunized may have mild manifestations and the exanthem can be typical, short lasting [4] or even absent [7,9], making a diagnosis difficult. In our study, one patient had only malar maculo-papular lesions that lasted for 20 days and another had short-lasting micropapular lesions, followed by malar lesions. However three cases had the exanthema found in children without AIDS [6], with an average duration of 10.8 days, showing the variable clinical aspects of this disease in patients with AIDS.

Palumbo et al. [6] described six measles cases in children with AIDS and in five of them there were pulmonary complications, with a $50 \%$ mortality rate.
In our study, bronchopneumonia occurred in three cases, with no deaths. Krasinski et al. [4] indicated that the high mortality rate may be due to the immunosuppression that follows the disease, associated with the immunosuppression caused by AIDS itself, since both viruses infect $\mathrm{CD}_{4}$ Tlymphocytes. A synergy between measles and malnourishment may also increase the incidence of complications.

We did not find the high mortality rate observed by Palumbo [6], probably because of recent therapeutic schemes, in which the use of various anti-retroviral medications in association allows a better control of AIDS and consequently a better nutritional state.

\section{Conclusion}

Measles in children with AIDS may appear in many different forms. Exanthema may be absent, serology is not always confirmatory, the skin histologic examination may be non-specific and yet the patient may have the disease. Evaluation of epidemiological data, thorough clinical examination and the search for a positive serology are important tools to establish a diagnosis.

\section{References}

1. Feigin R.D. Exantemas. In: Bergman R.E., Vaughan V.C., eds. NELSON Tratado de Pediatria. 13th ed. Rio de Janeiro: Guanabara Koogan, 1983: 532-4.

2. Weinberg S., Prose N.S., Kristal L. Color Atlas of Pediatric Dermatology. 3rd ed. New York: Mc Graw - Hill, 1998.

3. Suringa D.W.R., Bank L.J., Ackerman A.B. Role of measles virus in skin lesions and Koplick's spots. N Engl J Med 1970;283(21):1139-42.

4. Krasinski K., Borokowsky W. Measles and measles immunity in children infected with human immunodeficiency virus. JAMA 1989; 261(17):2512-6.

5. Centers for Diseases Control. Recommendation of the Immunization Practice Advisory Commitee: Measles prevention. MMWR Atlanta 1987;36:409-25.

6. Palumbo P., Hoyt L., Demasio K., et al. Population-based study of measles immunization in human immunodeficiency virus infected children. Ped Infect Dis J 1992;11(12):1008-14.

7. Nance K.V., Smith M.L., Joshi V.V. Cutaneous manifestations of acquired immunodeficiency syndrome in children. Int J Dermatol 1991;30(8):531-9. 
8. Dover J.S., Johnson R.A. Cutaneous manifestation of human immunodeficiency virus infection. Part 2 Arch Dermatol 1991;127(10):1549-58.

9. Markowitz L.E., Chandler F.W., Roland E.O., et al. Fatal measles pneumonia without rash in a child with AIDS. J Infect Dis 1988; 158(2):480-3.

10. Centers for Diseases Control. Revised classification system for human immunodeficiency virus infection in children less than 13 years of age. MMWR 1994;43(RR12):1-19.

11. Marques R.M., Marcondes E., Berquó E., et al. Crescimento e desenvolvimento pubertário em crianças e adolescentes brasileiros: altura e peso. São Paulo, ed. Brasileira de Ciências, 1982.

12. Secretaria Municipal de Saúde. Boletim epidemiológico de Curitiba. n 3 ano 10, 1998.

13. Lim W., Sadick N., Gupta A., et al. Skin diseases in children with HIV infection and their association with degree of immunosuppression. Int J Dermatol 1990;29(1):24-30.

14. Léauté-Labréze C., Niamba P., Douard D., et al. Cutaneous manifestations of paediatric HIV infection: A cohort study of 35 patients. Ann Dermatol Veneorol 1998;125 (S1P2):80.

15. El Hachem M., Bernardi S., Pianosi G., et al. Mucocutaneous manifestations in children with HIV infection and AIDS. Ped Dermatol 1998;15(6):429-34.

16. Mcnutt N.S., Kindel S., Lugo J. Cutaneous manifestations of measles in AIDS. J Cutan Pathol 1992;19(4):315-24.

17. Forsea D., Mardarescu M., Strauss L., et al. Cutaneous manifestations in AIDS children. Ann Dermatol Veneorol 1998;125(S1P3):80-1.

18. Rudy B.J., Rutstein R.M., Pinto M.J. Responses to measles immunization in children infected with human immunodeficiency virus. J Ped 1994; 125 (1):72-4.

19. Zolopa A.R., Kemper C.A., Shiboski S., et al. Progressive immunodeficiency due to infection with human immunodeficiency virus does not lead to waning immunity to measles in a cohort of homosexual men. Clin Infect Dis 1994;18:636-8. 